Bangladesh J. Sci. Ind. Res. 42(3), 357-360, 2007

Short communication

\title{
Development of Mechanical Device for the Addition of Dyes and Auxiliaries in Textile Wet Processing
}

\author{
M. M. Alam, M. M.U. Jubayer and M. A. Kaysar \\ Dyeing Divtion, Lethe group, Sonarpar, Dhaka, Bangladesh.
}

\begin{abstract}
In the exhaust dyeing of knit woven, jute/cotton fabrics a progressive addition process is developed and found most effective method in respect of cost and quality. It was done by an electronic device. In this paper we have developed it mechanically .It thought that it may be suitable for Bangladesh export oriented knit woven and blended fabrics dyeing units for its very low price.
\end{abstract}

\section{Introduction}

Auto dosing is a method of dosing chemical by which a chemical can be added in any chemical process as per required quantity at that stage .In this process normally a reactive chemical is added in progressive or regressive amount to make the reaction process always straight/steady. So that optimum result is obtained. The rate of forward chemical reaction is proportional to the active reactant at that stage (Paul and Chakraborty, 1979). So the speed of the reaction will be faster at the beginning and will be slower due to gradual reduction of the active chemicals. In the case of textile dyeing process progressive alkali dosing is adopted in an electrical device to get a maximum leveling of the dyeing. Since this is a computerized process it needs some skill of the operator and high cost. So we have developed a very low cost mechanical device in which the fixation (reaction curve) of the dyeing is to be controlled. It is studied that maximum unevenness is caused during fixation process. And it is happened for an uncontrolled addition of the alkali in the bath It is a net loss. Normally the fixation curve (reaction curve) is considered to control the fixation curve straight and the addition is done just reverse of the fixation curve .So the fixation curve become straight as per law of parallogram (Ishaq and Talukder, 1979) and the rate of dye fixation per unit time always remain same.

\section{Table and formula}

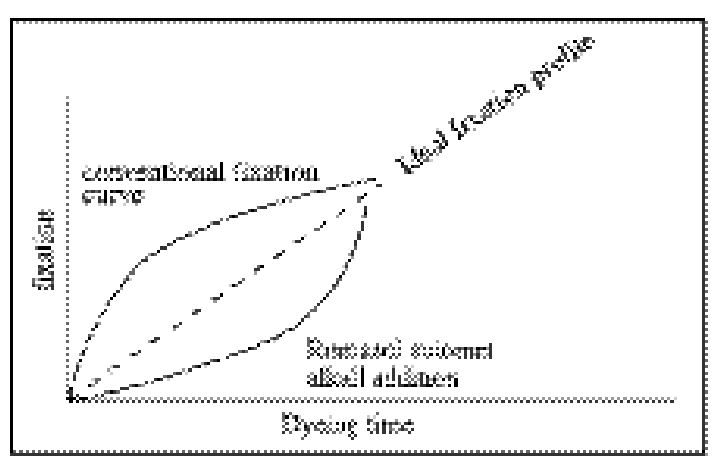


The volume of the liquor is given a graphical shape and is posted to a linear distance which is proportional to the addition time. Then the liquor is added as per graph

$\operatorname{rdM} .(\mathrm{P} / \mathrm{Q}) \cdot(\mathrm{G} / \mathrm{M} 1)=\mathrm{L}=\mathrm{T}$

$\mathrm{T}=$ Total Time, $\mathrm{L}=$ Length of the Traversing distance, $\mathrm{G}=$ Gear Constant, M1=Motor pulley dia $\mathrm{M}=$ Motor $\mathrm{rpm}, \mathrm{r}=\mathrm{rpm}$ of the last pulley, $\mathrm{d}=$ dia of the last pulley, $\mathrm{p}$, and $\mathrm{Q}$ is the dia of the intermediate pulley

Figure illustrates below the for the fixation pattern obtained by the addition of the alkali. Here :
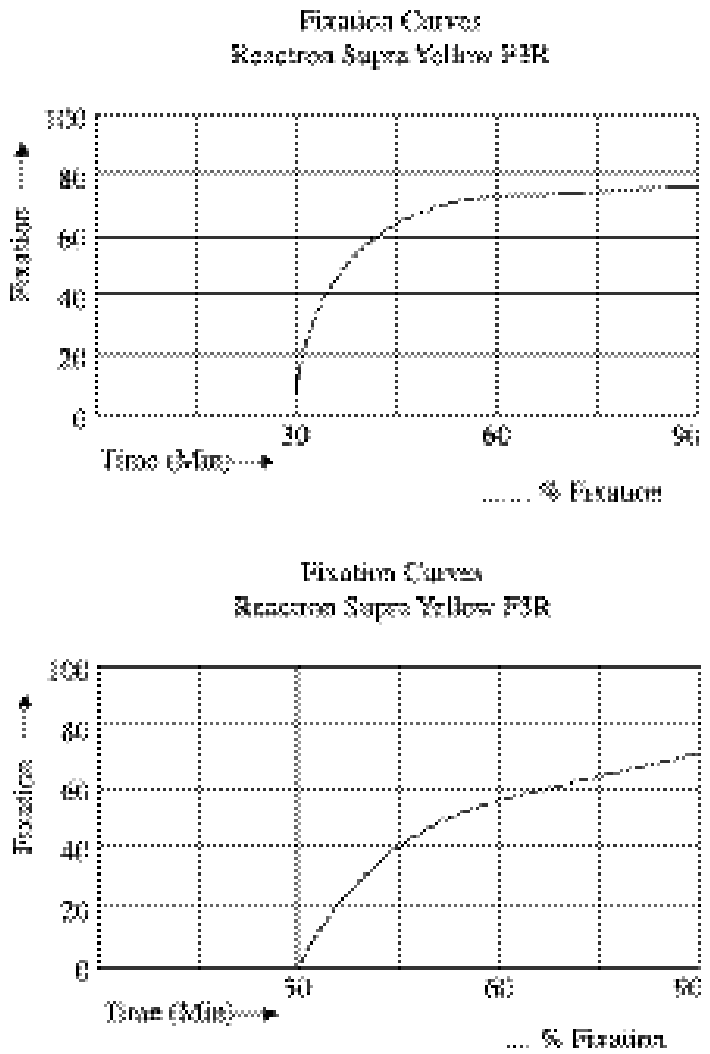
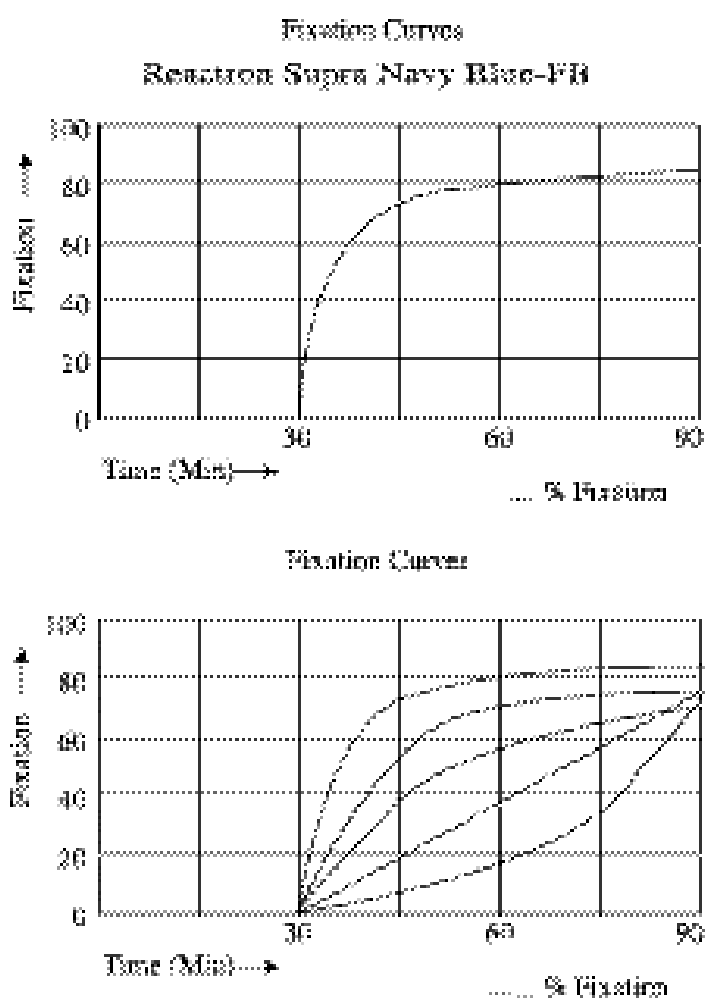

\section{Materials and Methods}

A small motor (A), gear box (B) say 1:100 a pulley (C) \& v-belt, a wooden box (KLMN) with hole in its wall were taken. It will be suitable to draw a graph on the wall of the box and plastic poly bag. Some thin rod is used to make this unit. The design of the unit is as follow

The gear box will above its last shaft only one revolution in total time and the plate of the side will be down to the bottom in that one revolution. The time in minute will be equal to the no of teeth in the pinion. 


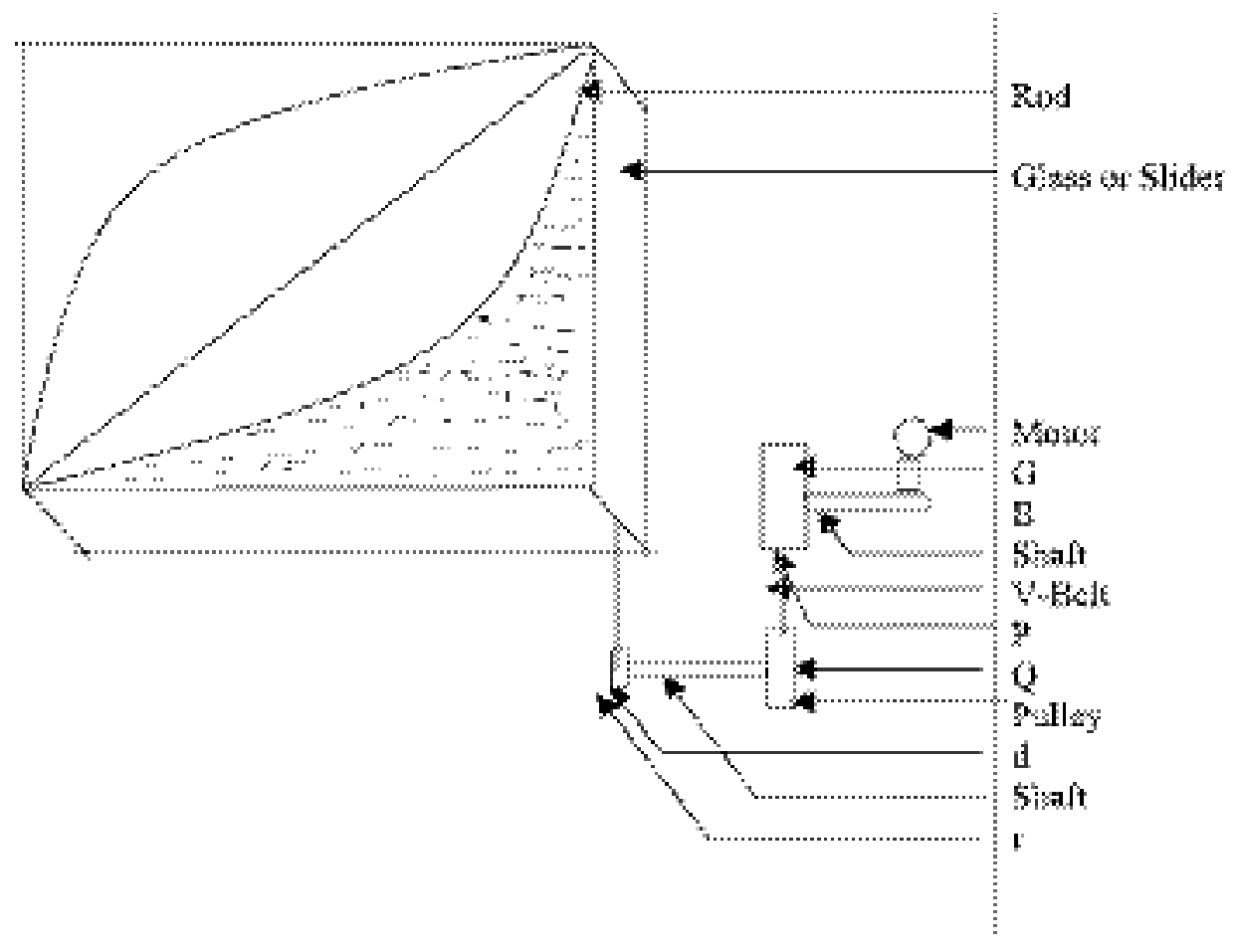

Say fixation time is 60 minute. So the number of teeth in the change pinion will be 60

An amount of caustic soda $2 \mathrm{kgs}$ was dissolved with a minimum quantity of water. Some thin iron rod was used to shape the graph (fixation curve) in the box. Then this caustic soda solution was transferred to the addition box in the plastic bag.. A few amount of extra water was used to fill up the bag upto the top end of the graph. The top end of the graph is the height of the box. The motor of the addition box was on. The addition observed was found as per graph. The procedure was done for 10 repeated times. The dyed samples was then tested in ISO standard method to determine the fastness properties.

\section{Results and Discussion}

It is seen that the addition of the liquor same as reverse of the fixation curve. Hence the leveling obtained was maximum. The addition amount of the liquor in different moment was progressively higher as per graph as seen in Table I and the reaction was progressively lower in the reaction curve. So the fixation per unit time was always same which guaranteed the excellent levelness of the dyed goods as seen in Table II.

A minimum problem builds the confidence of the dyers. It is also very economical for the dye house to use. A better control over the reaction process Easy to use by the layman. Hence, it is very feasible in industries. It is easy to operate by a layman, Problem minimizes, time saving, profit maximization. 
Table I. The result found was as follows

\begin{tabular}{|l|l|l|l|}
\hline No of test & 1 & 2 & 3 \\
\hline Set time & 60 & 60 & 60 \\
\hline Amount of liquor in 5 minute & 0.395 & 0.400 & .390 \\
\hline Amount of liquor in 10 minute & 1.944 & 1.947 & 1.948 \\
\hline Amount of liquor in 15 minute & 2.739 & 2.739 & 2.736 \\
\hline Amount of liquor in 20 minute & 5.001 & 5.001 & 5.000 \\
\hline Amount of liquor in 25 minute & 9.436 & 9.435 & 9.436 \\
\hline Amount of liquor in 30 minute & 13.240 & 13.242 & 13.241 \\
\hline Amount of liquor in 35 minute & 17.650 & 17.651 & 17.650 \\
\hline Amount of liquor in 40 minute & 27.396 & 27.39 & 27.38 \\
\hline Amount of liquor in 45 minute & 36.529 & 36.527 & 36.529 \\
\hline Amount of liquor in 50 minute & 50.536 & 50.532 & 50.532 \\
\hline Amount of liquor in 55 minute & 79.757 & 79.756 & 79.756 \\
\hline Amount of liquor in 60 minute & 99.995 & 100 & 99.990 \\
\hline
\end{tabular}

Table II. Result of the dyeing was a following

\begin{tabular}{|l|l|l|l|}
\hline lot & 1 & 2 & 3 \\
\hline leveling & Excellent & Excellent & Excellent \\
\hline & $4-5$ & 5 & 5 \\
\hline Crease Mark & No & No & NO \\
\hline $\begin{array}{l}\text { Rib body } \\
\text { shading }\end{array}$ & $\begin{array}{l}\text { Very } \\
\text { good }\end{array}$ & $\begin{array}{l}\text { Very } \\
\text { good }\end{array}$ & $\begin{array}{l}\text { Very } \\
\text { good }\end{array}$ \\
\hline $\begin{array}{l}\text { Roll to roll } \\
\text { Variation }\end{array}$ & No & No & No \\
\hline Reproducibility & Excellent & Excellent & Excellent \\
\hline
\end{tabular}

It is a very low cost unit. It can be started just after the previous stoppage that it will not recalculate the addition liquor after stoppage. It does not require any computer but it can also be used with a computer. It can work in a variable volume of the liquor .It is not a percent curve it follows exactly the graph It is easy to operate by a lay man. and very low cost .It can be started just after the previous stoppage that it will not recalculate the liquor after stoppage. Does not require any computer but it can work with the computer. It can work in a variable volume of the liquor.

It is not a percent curve it follows exactly the graph.

\section{References}

Degree Physical Chemistry by Suvash Chandra Paul and Poritosh Chakraborty 1979 3rd Edition,

Gund. Jousn. Soe, Dyes \& col- 1953 P 69, 671.

Higher Secondary Physics by Mohammad Ishaq and Nurunnabi Talukder p157

Published by Imperial chemical Industries Ltd, Dyestuff division 1962, procion dyestuff in Textile Dyeing. P-41 .

Received : December 21, 2005;

Accepted : April 09, 2007. 